\title{
Lung emptying in patients with acute respiratory distress syndrome: effects of positive end-expiratory pressure
}

\author{
E. Kondili, G. Prinianakis, H. Athanasakis, D. Georgopoulos
}

\begin{abstract}
Lung emptying in patients with acute respiratory distress syndrome: effects of positive end-expiratory pressure. E. Kondili, G. Prinianakis, H. Athanasakis, D. Georgopoulos. (C) ERS Journals Ltd 2002.

ABSTRACT: The pattern of lung emptying was studied in $\mathbf{1 0}$ mechanically-ventilated patients with acute respiratory distress syndrome.

At four levels of positive end-expiratory pressure (PEEP) $\left(0,5,10\right.$ and $\left.15 \mathrm{cmH}_{2} \mathrm{O}\right)$ tracheal $\left(P_{\text {tr }}\right)$ and airway pressures $(P$ aw $)$, flow $\left(V^{\prime}\right)$ and volume $(V)$ were continuously recorded. Tidal volume was set between $0.5-0.6 \mathrm{~L}$ and $V^{\prime} I V$ curves during passive expiration were obtained. Expired volume was divided into five equal volume slices and the time constant $(\tau e)$ and effective deflation compliance $\left(C_{r} s_{\text {fff }}\right)$ of each slice was calculated by regression analysis of $V I V^{\prime}$ and postocclusion $V I P$ tr relationships, respectively. In each slice, the presence or absence of flow limitation was examined by comparing $V^{\prime} / V$ curves with and without decreasing $P_{\text {aw. }}$. For a given slice, total expiratory resistance $(R$ tot) (consisting of the respiratory system $(R \mathrm{rs})$, endotracheal tube ( $R$ tube) and ventilator circuit $\left(R\right.$ vent)) was calculated as the $\tau \mathrm{e} / C_{\mathrm{rs}}$ eff ratio. In the absence of flow limitation $R$ rs was obtained by subtracting $R$ tube and $R$ vent from $R$ tot, while in the presence of flow limitation $R$ rs equaled $R$ tot. The $\tau$ e of the pure respiratory system ( $\tau$ ers) was calculated as the product of $R$ rs and $C_{\mathrm{rs}_{\text {eff }} \text {. }}$

At zero PEEP, $\tau$ ers increased significantly towards the end of expiration $(52 \pm 31 \%)$ due to a significant increase in $\operatorname{Rrs}(46 \pm 36 \%)$. Application of PEEP significantly decreased $R$ rs at the end of expiration and resulted in a faster and relatively constant rate of lung emptying.

In conclusion, without positive end-expiratory pressure the respiratory system in patients with acute respiratory distress syndrome deflates with a rate that progressively decreases, due to a considerable increase in expiratory resistance at low lung volumes. Application of positive end-expiratory pressure decreases the expiratory resistance, probably by preventing airway closure, and as a result modifies the pattern of lung emptying.
\end{abstract}

Eur Respir J 2002; 19: 811-819.

\author{
Dept of Intensive Care Medicine, Uni- \\ versity Hospital of Heraklion, Univer- \\ sity of Crete, Heraklion, Crete, Greece. \\ Correspondence: D. Georgopoulos \\ Dept of Intensive Care \\ University Hospital of Heraklion \\ University of Crete \\ Heraklion \\ Crete \\ Greece \\ Fax: 3081392636 \\ E-mail: georgop@med.uoc.gr
}

Keywords: Compliance

flow limitation

resistance

time constant

Received: June 252001

Accepted after revision January 72002

This study was supported by a grand from Cretan Critically Ill Association (CCIA).
Acute respiratory distress syndrome (ARDS) involves an overwhelming inflammatory reaction of the pulmonary parenchyma to a variety of serious underlying diseases $[1,2]$. ARDS affects adversely the mechanical properties of the respiratory system with reduced compliance and, to a lesser extent, increased resistance as hallmarks $[3,4]$. The syndrome is characterized by heterogeneous lung involvement, with relatively well preserved areas and severely diseased areas [5]. This heterogeneous involvement may affect the pattern of lung emptying during passive expiration. This pattern might also be influenced by the progress of the disease itself or by various therapeutic interventions, such as positive end-expiratory pressure (PEEP) application. Nevertheless, the pattern of lung emptying in ARDS patients has attracted little attention.

GutTMAnN et al. [6] observed that in patients with ARDS who were mechanically ventilated on PEEP, consecutive volume $(V)$ portions were exhaled with nearly identical time constants $(\tau e)$, as indicated by a relatively constant $V /$ flow $\left(V^{\prime}\right)$ relationship throughout expiration. This observation was attributed to to the presence of the endotracheal tube. Indeed, taking into account the resistance of the endotracheal tube and ventilator circuit, GUTTMAN et al. [6] recalculated the $\tau$ e of the pure respiratory system ( $\tau$ ers) and observed a progressive increase toward the end of expiration. However, in this study [6] the $\tau$ ers was calculated with the assumption that the respiratory system compliance did not differ between inspiration and expiration. The possibility of hysteresis [7] renders this assumption questionable. Furthermore, it has been shown that mechanically-ventilated patients with ARDS may exhibit flow limitation during tidal expiration [8]. In which case the endotracheal tube resistance (Rtube), as well as the expiratory ventilator circuit, may not affect the expiratory flow and, thus, the rate of lung emptying [9, 10]. It follows that calculating the $\tau$ ers without knowing if expiratory flow at the volume of interest is or is not limited might be misleading. Finally, GutTMANN et al. [6] studied the pattern of emptying with PEEP, which by changing the lung volume may modify regional $\tau$ ers. 
The purpose of the present study, was to re-evaluate the pattern of lung emptying in mechanically ventilated patients with ARDS, and to assess the effects of PEEP. The $\tau$ ers (without the endotracheal tube and expiratory ventilator circuit) was calculated at different PEEP levels using data obtained by expiratory $V^{\prime} / V$ and postocclusion pressure $(P) / V^{\prime}$ curves, taking into account the presence or absence of flow limitation during passive expiration. This might increase the understanding of the mechanistic behaviour of the respiratory system in ARDS patients.

\section{Methods}

Ten adult patients needing mechanical ventilation due to ARDS were studied prospectively. The diagnosis of ARDS was based on American-European Consensus Conference criteria [1]. Exclusion criteria included a previous history of obstructive lung disease or asthma, the presence of a chest tube with a persistent air leak and haemodynamic instability. The Institutional Ethics Committee approved the study and informed consent was obtained from each patient or next of kin.

All patients were orotracheally intubated with an endotracheal tube (inner diameter $7.5 \mathrm{~mm}$ in three patients, $8 \mathrm{~mm}$ in five and $8.5 \mathrm{~mm}$ in two) and ventilated (Servo Ventilator 300; Siemens, Solna, Sweden) on a volume-control mode using a constant inspiratory flow with settings determined by the primary physician (table 1). The patients were sedated with a continuous infusion of propofol-fentanyl and paralyzed with cisatracurium. Flow at the airway opening was measured with a heated pneumotachograph (adult size, HansRudolf 3700; Hans-Rudolf, KS, USA) and a differential pressure transducer (MicroSwitch 140PC; Honeywell Ltd, ON, Canada), both placed between the endotracheal tube and the Y-piece of the ventilator. A pneumatic-driven occlusion valve (Hans Rudolf 9300; Hans-Rudolf) was inserted between the pneumotachograph and the $\mathrm{Y}$-piece of the ventilator. Flow was electronically integrated to provide volume. Airway pressure $(P$ aw $)$ was measured from a side port between the pneumotachograph and the endotracheal tube. Tracheal pressure $(P \operatorname{tr})$ was measured with a polyethylene catheter (inner diameter $1.5 \mathrm{~mm}$ ) with multiple side holes and an occluded end hole, placed $2-3 \mathrm{~cm}$ past the carinal end of the endotracheal tube. Each signal was sampled at $150 \mathrm{~Hz}$ (Windaq Instruments Inc, OH, USA) and stored on computer disk for later analysis.

\section{Protocol}

Initially the inspiratory oxygen fraction $\left(F \mathrm{I}, \mathrm{O}_{2}\right)$ was increased to $100 \%$ and was maintained at this level throughout the study. Each patient was studied at four levels of PEEP $\left(0,5,10\right.$ and $\left.15 \mathrm{cmH}_{2} \mathrm{O}\right)$ applied randomly. At each level of PEEP the patients were ventilated with tidal volume $(V \mathrm{~T})$ and a breathing frequency similar to those determined by the primary physician. When the patients were stable at each PEEP level (at least $15 \mathrm{~min}$ ) $V \mathrm{~T}$ was set between 0.5 $0.6 \mathrm{~L}$, given with constant inspiratory flow, a ventilator frequency of $10 \mathrm{breaths} \cdot \mathrm{min}^{-1}$ and inspiratory time/total breath time of 0.3 . To ensure that these settings resulted in a end-expiratory lung volume that reached passive functional residual capacity (FRC) determined by PEEP level, the expiratory line of the ventilator at the end of expiration was occluded by pressing the end-expiratory hold button. If there was an increase in $P$ aw after end-expiratory occlusion, indicating intrinsic PEEP (PEEPi), $V \mathrm{~T}$ was further decreased until end-expiratory occlusion did not demonstrate the existence of PEEPi. With these settings the patients were ventilated for 10 breaths to standardize the volume history. In the following breath, (study breath), the airways were occluded at end-inspiration for $3 \mathrm{~s}$ using the end-inspiratory hold button of the ventilator. After the release of the occlusion various manipulations were performed as follows. 1) The patient was permitted to exhale to passive FRC, determined by the PEEP level. For a given level of PEEP at least 5-7 breaths with uninterrupted expiration to passive FRC were collected. These breaths were averaged to give a single expiratory $V^{\prime} / V$ curve. 2) Airway occlusions lasting $3 \mathrm{~s}$ were performed randomly at different points during expiration. Each study breath was occluded once during expiration after the release the end-inspiratory occlusion. The occlusion was

Table 1. - Patient characteristics and baseline ventilator settings

\begin{tabular}{|c|c|c|c|c|c|c|c|c|c|}
\hline $\begin{array}{l}\text { Patient } \\
\text { no. }\end{array}$ & $\begin{array}{l}\text { Age } \\
\text { yrs }\end{array}$ & Sex & $\begin{array}{l}\mathrm{BW} \\
\mathrm{kg}\end{array}$ & $\begin{array}{l}\text { PEEP } \\
\mathrm{cmH}_{2} \mathrm{O}\end{array}$ & $V \mathrm{~T} \mathrm{~L}$ & $\begin{array}{c}\mathrm{Fr} \\
\mathrm{br} \cdot \mathrm{min}\end{array}$ & $\begin{array}{l}\text { Days } \\
\text { on MV }\end{array}$ & $\begin{array}{c}\text { ALI } \\
\text { score }\end{array}$ & $\begin{array}{l}\text { Cause of } \\
\text { ARDS }\end{array}$ \\
\hline 1 & 62 & M & 77 & 7 & 0.46 & 19 & 7 & 2 & Aspiration \\
\hline 2 & 50 & M & 85 & 6 & 0.52 & 20 & 9 & 2.3 & Pneumonia \\
\hline 3 & 52 & M & 75 & 8 & 0.50 & 21 & 4 & 2.3 & Aspiration \\
\hline 4 & 35 & $\mathrm{~F}$ & 79 & 5 & 0.31 & 30 & 3 & 2 & Sepsis \\
\hline 5 & 73 & $\mathrm{~F}$ & 68 & 8 & 0.42 & 24 & 5 & 2 & Sepsis \\
\hline 6 & 38 & $\mathrm{~F}$ & 70 & 5 & 0.40 & 20 & 5 & 2 & Pneumonia \\
\hline 7 & 65 & M & 72 & 9 & 0.50 & 15 & 2 & 3 & Aspiration \\
\hline 8 & 63 & $\mathrm{~F}$ & 65 & 8 & 0.48 & 15 & 5 & 2.3 & Aspiration \\
\hline 9 & 68 & $\mathrm{~F}$ & 72 & 8 & 0.49 & 21 & 6 & 2.3 & Pneumonia \\
\hline 10 & 40 & $\mathrm{~F}$ & 82 & 8 & 0.45 & 28 & 4 & 2.6 & Sepsis \\
\hline
\end{tabular}

BW: body weight; PEEP: positive end-expiratory pressure; $V \mathrm{~T}$ : tital volume; Fr: ventilator frequency; MV: mechanical ventilation; ALI: acute lung injury; ARDS: acute respiratory distress syndrome; M: male; F: female. 
performed manually with the pneumatic occlusion valve. In each subject and for a given level of PEEP, at least 20 airway occlusions during expiration were performed to obtain data throughout expiration. $P \operatorname{tr}$ exhibited two distinct pressure changes after interruption, an initial rapid increase to one level $\left(P_{t_{i n i t}}\right)$ followed by a slower increase to a plateau value $\left(P \operatorname{tr}_{\mathrm{p}}\right)$. $P \operatorname{tr}_{\text {init }}$ was considered the effective recoil pressure for expiratory flow, whereas $P \operatorname{tr}_{\mathrm{p}}$ was the static elastic recoil pressure [11-13]. In order to deal with oscillations in the pressure signal, $P \operatorname{tr}_{\text {init }}$ was measured by fitting a smooth curve to the postocclusion portions of the pressure signal and extrapolating the fitted curve to the point in time where $V^{\prime}$ was zero, as previously described [13]. $P \operatorname{tr}_{\mathrm{p}}$ was measured at $3 \mathrm{~s}$ after occlusion. By plotting $P \operatorname{tr}_{\text {init }}$ and $P \operatorname{tr}_{p}$ against the corresponding $V$ above passive FRC at zero PEEP (ZEEP) (FRCZEEP, see later) $P \operatorname{tr}_{\text {init }} / V$ and $P \operatorname{tr}_{\mathrm{p}} / V$ curves were constructed at all PEEP levels. 3) With ZEEP, passive expiration was performed directly to the atmosphere by removing the expiratory ventilator circuit during the preceding end-inspiratory occlusion. When PEEP was applied the PEEP was reduced by $2 \mathrm{cmH}_{2} \mathrm{O}$ during the end-inspiratory occlusion and the patient was permitted to exhale to the new PEEP level. For a given PEEP (or ZEEP) 5-7 breaths were collected. These breaths were averaged to give a single expiratory $V^{\prime} / V$ curve, which was compared with the corresponding expiratory $V^{\prime} / V$ curve obtained during passive uninterrupted expiration to ZEEP or various PEEP levels in order to assess the presence or absence of flow limitation (see later) [14]. 4) When PEEP was applied it was removed during the end-inspiratory occlusion and the patient exhaled passively to ZEEP. The end-expiratory volume difference between ZEEP and PEEP was the change in end-expiratory lung $V$ induced by PEEP. This procedure was performed once.

The first three manipulations were performed randomly, while the fourth was performed at the end before changing the PEEP level.

\section{Data analysis}

Assessment of flow limitation. At ZEEP the average $V^{\prime} / V$ curve obtained during expiration to FRCZEEP was superimposed on the $V^{\prime} / V$ curve obtained when the patient exhaled directly into the atmosphere by removing the expiratory ventilator circuit. With PEEP the average $V^{\prime} / V$ curve obtained during expiration to PEEP level was superimposed on the average $V^{\prime} / V$ obtained during expiration to the new PEEP which was $2 \mathrm{cmH}_{2} \mathrm{O}$ lower than the corresponding PEEP level. Therefore, for a given PEEP (or ZEEP), the $V^{\prime} / V$ curve was obtained with and without decreasing the downstream pressure. The two $V^{\prime} / V$ curves were superimposed assuming that the end-inspiratory lung level was identical under both conditions, as indicated by a similar $P \operatorname{tr}$ at the end of inspiratory occlusion. The presence of flow limitation was assessed by comparing expiratory $V^{\prime}$ over a given portion of lung $V[8,10,14]$. If expiratory $V^{\prime}$ was consistently higher when downstream $P$ was lowered by removing the expiratory
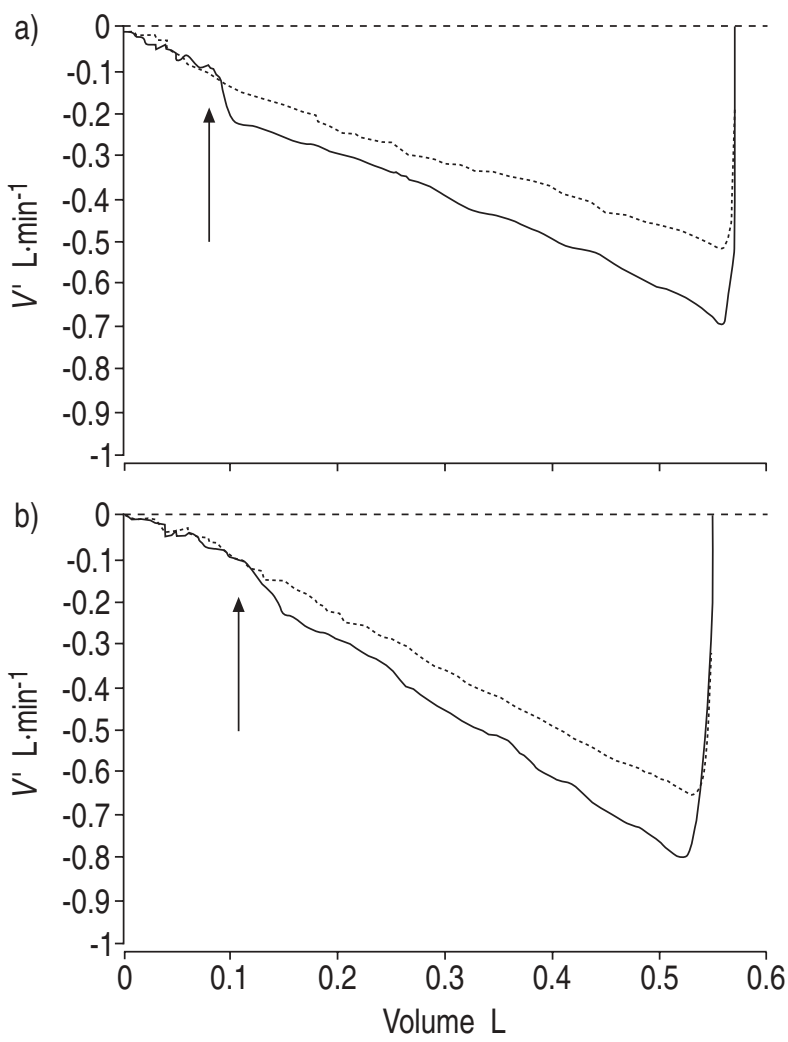

Fig. 1.-Expiratory flow/volume $\left(V^{\prime} / V\right)$ curves, obtained at zero positive end-expiratory pressures (PEEP) with (- -) and without $(-)$ the ventilator expiratory circuit, in two representative patients (a and b). Arrows: $V^{\prime}$ became similar $\left( \pm 0.02 \mathrm{~L} \cdot \mathrm{sec}^{-1}\right)$ at $90 \mathrm{~mL}$ and $120 \mathrm{~mL}$ above end-expiratory lung $V$ in patients a and $\mathrm{b}$, respectively.

ventilator circuit or decreasing the PEEP level, the $V$ portion was classified as being without flow limitation (fig. 1). If decreasing the downstream $P$ caused expiratory $V^{\prime}$ to be similar $\left( \pm 0.02 \mathrm{~L} \cdot \mathrm{s}^{-1}\right)$ to that achieved with the higher downstream $P$ the $V$ portion was classified as having flow limitation. In all cases the onset of flow limitation was easily identified by a knee in the $V^{\prime} / V$ curve (fig. 1). The extent of flow limitation was quantified in terms of the portion of $V \mathrm{~T}$ over which the expiratory $V^{\prime}$ were similar under both conditions and was expressed as $\%$ of the $V \mathrm{~T}$.

\section{Determination of the pattern of emptying}

The pattern of emptying was assessed using the method of GuTTMAnN et al. [6]. Briefly, at each PEEP level the average $V^{\prime} / V$ curve during uninterrupted expiration was analysed. $V$ was plotted against $V^{\prime}$ and the inflection point (IP) of the curve, defined as the point of maximum slope of the curve following the expiratory peak flow, was identified [6]. Early expiration from the beginning to IP, was assumed to be influenced to some extent by inertial effects and, therefore, was not used for further analysis. In some cases IP could not be identified, probably because peak expiratory flows were relatively low. In these cases the initial $0.06 \mathrm{~L}$ of the expired volume, which 
was equal to the average volume from the beginning of expiration to IP, was not used for analysis. The expired $V$ from IP to the end of expiration was then subdivided into five consecutive slices of equal size (90-100 mL each). Each $V$ slice was treated as if it came from a single compartment model of constant compliance served by a pathway of constant resistance. In this case passive expiration follows a monoexponential pattern with a $\tau$ e given by the product of respiratory system deflation compliance and total flow resistance ( $R$ tot). This can be obtained from the slope of $V / V^{\prime}$ relationship $[6,15,16]$.

For a given $V$ slice, $R$ tot was calculated as the ratio $\tau \mathrm{e} / C_{\mathrm{rs}} \mathrm{sff}_{\text {f }}$, where $C \mathrm{rs}_{\mathrm{eff}}$ was the effective deflation compliance, defined as the slope of $V / P \operatorname{tr}_{\text {init }}$ relationship, obtained by linear regression analysis of the deflation $P \operatorname{tr}_{\text {init }} / V$ curve at the $V$ of interest. Although in order to construct the $P \operatorname{tr}_{\text {init }} / V$ curve for a given PEEP, at least 20 points were obtained, the number of points was not sufficient for some $V$ slices. For this reason the $P \operatorname{tr}_{\text {init }} / V$ curve was described using the sigmoidal equation proposed by VENEGAS et al. [17] and Harris et al. [18] and described previously [16, 19] of the form:

$$
V=\mathrm{a}+\mathrm{b}\left(1+\mathrm{e}^{-(\mathrm{P}-\mathrm{c}) / \mathrm{d}}\right)^{-1}
$$

where $\mathrm{P}$ is the pressure at a given $V$ above endexpiratory lung volume and $\mathrm{a}, \mathrm{b}, \mathrm{c}$ and $\mathrm{d}$ are constants. Thus, at each PEEP the $P \operatorname{tr}_{\text {init }} / V$ relationship during expiration was described by a curve consisting of several points (fig. 2). Considering that in each $V$ slice $C \mathrm{rs}_{\text {eff }}$ was constant, linear regression analysis on points obtained by equation 1 was performed and $C \mathrm{rs}_{\text {eff }}$ of the $V$ slice was determined as the slope of the $V / P \operatorname{tr}_{\text {init }}$ relationship (fig. 2). Similar analysis was performed with the $P \operatorname{tr}_{\mathrm{p}} / V$ curve yielding the static deflation compliance of respiratory system $(C \mathrm{rs})$.

$V$ slices were considered to be nonflow limited if at least $95 \%$ of the $V$ slice expiratory $V^{\prime}$ were consistently higher when $P$ aw was lowered. In these slices $\tau$ ers was calculated as the product of $C_{\mathrm{rs}_{\mathrm{eff}}}$ and the resistance of the respiratory system $(R \mathrm{rs})$. $R$ rs was calculated by subtracting from $R$ tot the endotracheal tube (Rtube) and expiratory ventilator circuit ( $R$ vent) resistances. $R$ tube and $R$ vent were directly obtained by dividing the difference between $P$ tr and $P$ aw, and $P$ aw and PEEP by the corresponding expiratory $V^{\prime}$, respectively. Because $R$ tube and $R$ vent were flow dependant, for a given $V$ slice the different values of $R$ tube and $R$ vent obtained by the sampling rate of $P$ and $V^{\prime}$ (sampling rate $150 \mathrm{~Hz}$ ), were averaged to give a single value of $R$ tube and $R$ vent, which pertained to the $V$ of interest (mean $R$ tube and $R$ vent).

In the presence of flow limitation during at least $95 \%$ of the $V$ slice, $\tau$ e obtained from the slope of the $V / V^{\prime}$ relationship and $R$ tot calculated from $\tau e / C \mathrm{rs}_{\mathrm{eff}}$ ratio were considered, respectively, to be the $\tau$ ers and $R$ rs. In the presence of flow limitation during a portion of the $V$ slice $>5 \%$ of the total $V$ slice, the flow- and nonflow-limited segments were analysed separately, as described earlier for $V$ slices with and without flow limitation. The $R$ rs of that $V$ slice was calculated by adding the Rrs of the flow and nonflow-limited
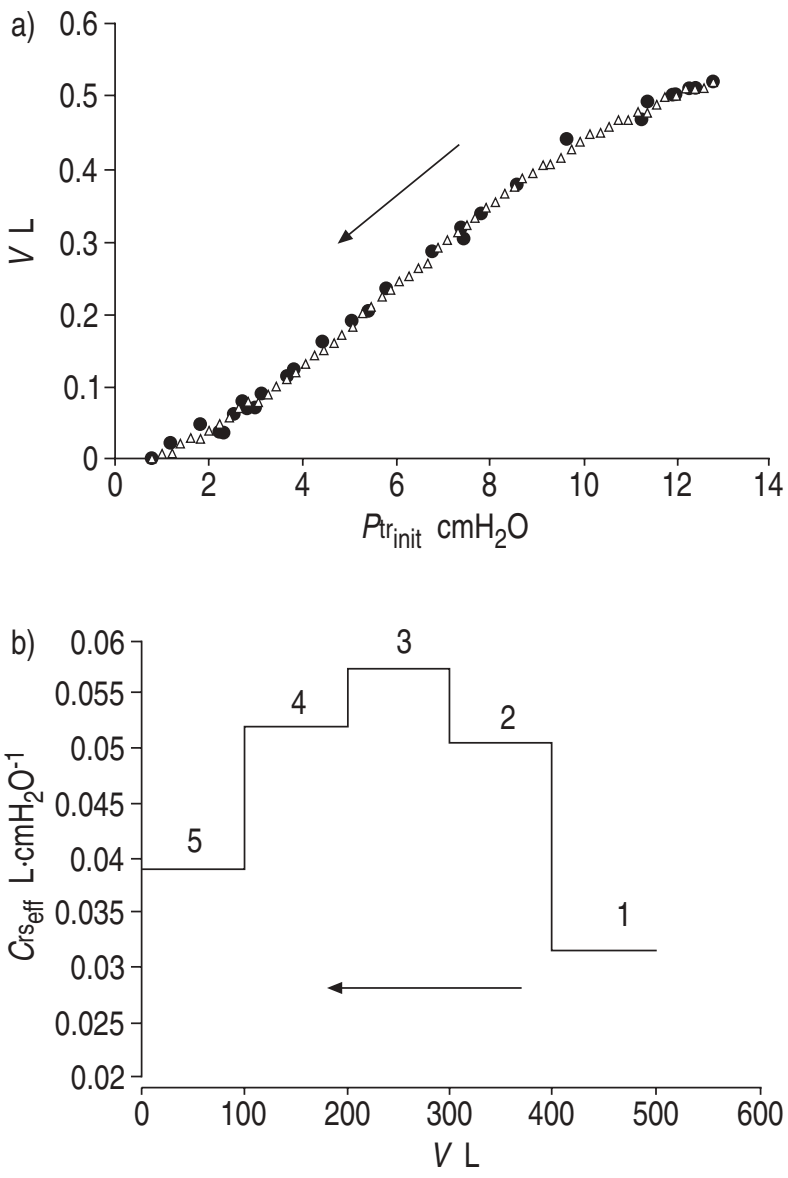

Fig. 2.-a) The initial rapid increase of tracheal pressure/volume $\left(P \operatorname{tr}_{\text {init }} / V\right)$ curve of the respiratory system in a representative patient. $\bigcirc$ : data points. $\triangle$ : points obtained by the equation curve fitted to the data. b) Effective deflation compliance $\left(C_{\mathrm{rs}} \mathrm{eff}\right)$ calculated by linear regression analysis on points obtained with the equation curve fitted to the data for each of the five consecutive volume slices (number 1-5, $100 \mathrm{~mL}$ each). Arrows indicate the direction of expiration.

segments, corrected for their contribution to the $R$ tot according to the following equation:

$$
R_{\mathrm{rs}}=R_{\mathrm{rs}} \mathrm{FL} \times \mathrm{FL}+R_{\mathrm{rs}_{\mathrm{NFL}}} \times \mathrm{NFL}
$$

where $R \mathrm{rs}_{\mathrm{FL}}$ and $R \mathrm{rs}_{\mathrm{NFL}}$ are the respiratory system expiratory resistances of flow-limited and nonflowlimited segments, respectively. FL and NFL were volumes, expressed as $\%$ of the $V$ slice, of flow-limited and nonflow-limited segments, respectively.

The end-inspiratory resistance of the respiratory system was also measured using the occlusion technique [20, 21]. Under all conditions, inspiratory $V^{\prime}$ rate and time were identical. Minimum $(R \min )$ and maximum $(R \max )$ inspiratory resistances of the respiratory system were computed according to standard formulas [20, 21] and procedures [22]. The difference between $R \max$ and $R \min (\Delta \mathrm{R})$ was also calculated.

Data were analysed by multifactorial analysis of variance (ANOVA) for repeated measurements. When the F value was significant, Tukey's test was used to identify significant differences. Linear regression analysis was performed with the least square method. 
Table 2. - End-inspiratory resistance of respiratory system with different positive end-expiratory pressure (PEEP) levels

\begin{tabular}{lrrrr}
\hline PEEP $\mathrm{cmH}_{2} \mathrm{O}$ & \multicolumn{1}{c}{} & \multicolumn{1}{c}{5} & \multicolumn{1}{c}{10} & 15 \\
\hline$R \max \mathrm{cmH}_{2} \mathrm{O} \cdot \mathrm{L}^{-1} \cdot \mathrm{s}^{-1}$ & $10.75 \pm 3.0$ & $12.33 \pm 5.9$ & $14.09^{\#} \pm 6.1$ & $17.52^{\#} \pm 7.0$ \\
$R \operatorname{min~cmH} \mathrm{C}_{2} \mathrm{O} \cdot \mathrm{L}^{-1} \cdot \mathrm{s}^{-1}$ & $4.21 \pm 1.8$ & $4.27 \pm 1.7$ & $4.08 \pm 1.8$ & $4.82 \pm 2.2$ \\
$\Delta \mathrm{R} \mathrm{cmH} \mathrm{C}_{2} \mathrm{O} \cdot \mathrm{L}^{-1} \cdot \mathrm{s}^{-1}$ & $6.54 \pm 2.3$ & $8.06 \pm 4.6$ & $10.01^{\#} \pm 5.1$ & $12.70^{\#} \pm 5.8$ \\
\hline
\end{tabular}

Data are presented as mean \pm SD. $R \max$ : maximum end-inspiratory resistance; $R$ min: minimum end-inspiratory resistance; $\Delta \mathrm{R}$ : difference between $R \max$ and $R$ min. ${ }^{\#}$ : significantly different from the value at zero PEEP.

A value of $p<0.05$ was considered statistically significant. Data were expressed as mean \pm SD.

\section{Results}

Mean expired $V \mathrm{~T}$ of the test breath was $0.56 \pm 0.061$, $0.54 \pm 0.07,0.53 \pm 0.07$ and $0.52 \pm 0.07 \mathrm{~L}$, respectively with $0,5,10$ and $15 \mathrm{cmH}_{2} \mathrm{O}$ PEEP $(\mathrm{p}>0.05)$. The analysed $V$ slice averaged $0.10 \pm 0.01,0.10 \pm 0.01,0.10 \pm$ 0.02 and $0.09 \pm 0.01 \mathrm{~L}$, respectively with $0,5,10$ and $15 \mathrm{cmH}_{2} \mathrm{O}$ of PEEP $(\mathrm{p}>0.05)$.

At ZEEP, nine patients exhibited flow limitation during tidal expiration, which ranged $8-25 \%$ of $V$ T of the study breath. In eight patients the last $V$ slice was considered to be flow limited. In one patient flow limitation was observed during the last $50 \mathrm{~mL}$ of the fifth $V$ slice. In six patients the fourth $V$ slice also had a flow limited segment which ranged between $25-44 \%$ of the $V$ slice. In all patients the first three $V$ slices were nonflow limited. With PEEP, flow limitation during tidal expiration was eliminated in all patients.

In all cases and independent of the conditions studied, the sigmoidal equation of VENEGAs et al. [16] was fitted to the $P \operatorname{tr}_{\text {init }} / V$ and $P \operatorname{tr}_{\mathrm{p}} / V$ data adequately, yielding coefficient of determination $\left(\mathrm{r}^{2}\right)$ values $>0.98$. Similarly in each $V$ slice the $V / P \operatorname{tr}_{\text {init }}$ and $V / P \operatorname{tr}_{\mathrm{p}}$ relationships were described with excellent accuracy by linear regression $\left(r^{2}>0.99\right)$. Furthermore, in each $V$ slice the $V / V^{\prime}$ relationship was highly linear $\left(\mathrm{r}^{2}>0.95\right)$.

For a given $V$ slice $R$ tube and $R$ vent differed between the beginning and end of the slice by $\sim 1$ and $0.5 \mathrm{cmH}_{2} \mathrm{O} \cdot \mathrm{L}^{-1} \cdot \mathrm{s}^{-1}$, respectively. In the first $V$ slice mean Rtube was $4.6 \pm 0.8,4.8 \pm 0.8,4.8 \pm 0.9$ and $5.0 \pm$ $0.8 \mathrm{cmH}_{2} \mathrm{O} \cdot \mathrm{L}^{-1} \cdot \mathrm{s}^{-1}$, respectively with $0,5,10$ and $15 \mathrm{cmH}_{2} \mathrm{O}$ PEEP and decreased to $0.8 \pm 0.2,0.9 \pm 0.2$, $0.9 \pm 0.3$ and $0.9 \pm 0.2$ by the fifth slice. The corresponding values of mean $R$ vent in the first slice were $5.7 \pm 0.5$, $4.5 \pm 0.7,4.6 \pm 0.7$ and $4.5 \pm 0.7$ and decreased to $3.3 \pm 1.1$, $3.6 \pm 1.1,3.3 \pm 1.0$ and $3.4 \pm 1.1$ by the fifth.

$R \max$ increased significantly with increasing PEEP. This increase was mainly due to a significant increase in the difference between Rmax and Rmin, whereas $R$ min remained relatively stable (table 2 ).

The difference between $P \operatorname{tr}_{\mathrm{p}}$ and $P \operatorname{tr}_{\text {init }}$ did not differ as a function of PEEP, averaging at midtidal $V 1.0 \pm 0$. $1,0.8 \pm 0.4,1.0 \pm 0.3$ and $1.1 \pm 0.6 \mathrm{cmH}_{2} \mathrm{O}$, respectively with $0,5,10$ and $15 \mathrm{cmH}_{2} \mathrm{O}$ PEEP. Independent of PEEP at the fifth $V$ slice $C$ rs $_{\text {eff }}$ was slightly but significantly higher than $C$ rs. For the remaining slices $C$ rs $_{\text {eff }}$ and $C$ rs did not differ ( $C$ rs data not shown).

Table 3 shows $\tau$ e, $C \mathrm{rs}_{\text {eff }}$ and $R$ tot of the consecutive $V$ slices with different PEEP. With ZEEP $\tau$ e decreased significantly from the beginning (first slice) to the end of expiration (fifth slice). This difference decreased progressively with increasing PEEP so that at 10 and

Table 3. - Time constant ( $\tau e)$, deflation compliance $\left(C_{r s}\right.$ eff $)$ and total flow resistance $(R$ tot $)$ of the consecutive volume slices at different positive end-expiratory pressure (PEEP)

\begin{tabular}{|c|c|c|c|c|}
\hline PEEP $\mathrm{cmH}_{2} \mathrm{O}$ & 0 & 5 & 10 & 15 \\
\hline \multicolumn{5}{|l|}{$\begin{array}{l}\text { Volume slice } \\
\tau \text { e sec }\end{array}$} \\
\hline 1 & $0.91 \pm 0.3^{\#}$ & $0.81 \pm 0.2^{\#}$ & $0.70 \pm 0.2^{\top}$ & $0.65 \pm 0.2$ \\
\hline 2 & $0.88 \pm 0.3^{\#}$ & $0.81 \pm 0.2^{\#}$ & $0.76 \pm 0.2$ & $0.70 \pm 0.2^{\top}$ \\
\hline 3 & $0.85 \pm 0.3^{\#}$ & $0.83 \pm 0.3^{\#}$ & $0.81 \pm 0.3$ & $0.70 \pm 0.2$ \\
\hline 4 & $0.78 \pm 0.2$ & $0.73 \pm 0.2$ & $0.74 \pm 0.3$ & $0.70 \pm 0.3^{\bullet}$ \\
\hline 5 & $0.70 \pm 0.2$ & $0.68 \pm 0.2$ & $0.71 \pm 0.3$ & $0.64 \pm 0.2$ \\
\hline \multicolumn{5}{|c|}{$C_{\mathrm{rs}_{\text {eff }}} \mathrm{L} \cdot \mathrm{cmH}_{2} \mathrm{O}^{-1}$} \\
\hline 2 & $0.052 \pm 0.02$ & $0.055 \pm 0.02$ & $0.048 \pm 0.01$ & $0.044 \pm 0.01^{\#}$ \\
\hline 3 & $0.057 \pm 0.02^{\#}$ & $0.059 \pm 0.02$ & $0.055 \pm 0.02$ & $0.052 \pm 0.02$ \\
\hline 4 & $0.057 \pm 0.02^{\#}$ & $0.059 \pm 0.01$ & $0.060 \pm 0.02$ & $0.059 \pm 0.02$ \\
\hline 5 & $0.048 \pm 0.01$ & $0.058 \pm 0.02$ & $0.062 \pm 0.02^{\bullet}$ & $0.059 \pm 0.02$ \\
\hline \multicolumn{5}{|c|}{$R$ tot $\mathrm{cmH}_{2} \mathrm{O} \cdot \mathrm{L}^{-1} \cdot \mathrm{s}^{-1}$} \\
\hline 1 & $20.6 \pm 3.3^{\#}$ & $18.2 \pm 3.4^{\#}$ & $18.0 \pm 3.8^{\#}$ & $20.1 \pm 3.5^{\#}$ \\
\hline 2 & $17.6 \pm 3.8$ & $15.4 \pm 2.6^{\#}$ & $16.3 \pm 2.8^{\#}$ & $16.2 \pm 2.1^{\#}$ \\
\hline 3 & $15.0 \pm 3.1$ & $14.1 \pm 1.5$ & $14.6 \pm 2.4$ & $13.5 \pm 1.8$ \\
\hline 4 & $13.8 \pm 1.3$ & $12.4 \pm 1.9$ & $12.3 \pm 1.6$ & $11.8 \pm 1.9$ \\
\hline 5 & $14.9 \pm 2.4$ & $11.6 \pm 1.6^{\circ}$ & $11.2 \pm 1.7^{\bullet}$ & $10.9 \pm 2.6^{\oplus}$ \\
\hline
\end{tabular}

${ }^{\#}$ : significantly different from the value of the fifth volume slice; ${ }^{\top}$ : significantly different from the value of the corresponding volume slice with zero PEEP. 
$15 \mathrm{cmH}_{2} \mathrm{O}$ PEEP $\tau$ e remained relatively constant throughout expiration. With ZEEP $C_{\text {rs }}$ eff was relatively low at the first and fifth $V$ slice, the maximum $C \mathrm{rs}_{\text {eff }}$ being observed at midtidal $V$. This pattern was altered significantly by PEEP. Independant of PEEP $R$ tot was significantly higher at the beginning than that at the end of expiration. With ZEEP $R$ tot of the fifth $V$ slice was significantly higher than the corresponding value with PEEP.

With ZEEP, ters and Rrs increased significantly at the end of expiration (table 4). With PEEP, ters also tended to increase toward the end of expiration, but the difference was not significant. With, ZEEP Rrs of the fifth $V$ slice was significantly higher than the corresponding value with PEEP. At the end of expiration (fifth slice) $\tau$ ers was significantly lower with PEEP than with ZEEP.

As an index of the overall rate of lung emptying, the mean $\tau$ e and $\tau$ ers of all $V$ slices for a given PEEP were calculated (fig. 3). Mean $\tau$ e and mean $\tau$ ers decreased significantly with increasing PEEP.

Compared to ZEEP, end-expiratory lung $V$ increased progressively with increasing PEEP, the increase averaging $0.27 \pm 0.1,0.61 \pm 0.2$ and $1.00 \pm$ $0.33 \mathrm{~L}$, with 5,10 and $15 \mathrm{cmH}_{2} \mathrm{O}$ of PEEP, respectively. The effect of PEEP on the $P \operatorname{tr}_{\mathrm{p}} / V$ curve is shown in figure 4. For the whole group the $P \operatorname{tr}_{\mathrm{p}} / V$ curve was displaced upward by each level of PEEP, indicating further recruitment. As an index of recruitment, the $V$ for a given $P \operatorname{tr}_{\mathrm{p}}$ between 0 and 5, 5 and 10 and 10 and $15 \mathrm{cmH}_{2} \mathrm{O}$ PEEP were compared, where data were available. At $P \operatorname{tr}_{p}$ of $5.2 \pm 1.0 \mathrm{cmH}_{2} \mathrm{O}$ (endexpiratory pressure with $5 \mathrm{cmH}_{2} \mathrm{O}$ PEEP) the difference in lung $V$ above FRCZEEP between ZEEP and $5 \mathrm{cmH}_{2} \mathrm{O}$ PEEP was $0.08 \pm 0.06 \mathrm{~L}(\mathrm{p}>0.05)$. Similar comparisons between 5 and $10 \mathrm{cmH}_{2} \mathrm{O}$ PEEP revealed that at $P \operatorname{tr}_{\mathrm{p}}$ of $10.1 \pm 1.1 \mathrm{cmH}_{2} \mathrm{O}$ the $V$ above FRCZEEP differed by $0.08 \pm 0.10 \mathrm{~L}(\mathrm{p}>0.05)$, while the corresponding value between $10-15 \mathrm{cmH}_{2} \mathrm{O}$ PEEP at $P \operatorname{tr}_{\mathrm{p}}$ of $15.0 \pm 1.2 \mathrm{cmH}_{2} \mathrm{O}$ was $0.17 \pm 0.11 \mathrm{~L}(\mathrm{p}<0.05)$.

Table 4. - Time constant ( $\tau$ ers) and resistance (Rrs) of the respiratory system of the consecutive volume slices at different positive end-expiratory pressure (PEEP)

\begin{tabular}{|c|c|c|c|c|}
\hline PEEP $\mathrm{cmH}_{2} \mathrm{O}$ & 0 & 5 & 10 & 15 \\
\hline \multicolumn{5}{|l|}{$\begin{array}{l}\text { Volume slice } \\
\tau \text { ers } \mathbf{S}\end{array}$} \\
\hline 1 & $0.45 \pm 0.1^{\#}$ & $0.39 \pm 0.1$ & $0.35 \pm 0.2$ & $0.34 \pm 0.1$ \\
\hline 2 & $0.48 \pm 0.2^{\#}$ & $0.37 \pm 0.1$ & $0.41 \pm 0.1$ & $0.36 \pm 0.1$ \\
\hline 3 & $0.42 \pm 0.2^{\#}$ & $0.42 \pm 0.2$ & $0.46 \pm 0.2$ & $0.36 \pm 0.1$ \\
\hline 4 & $0.50 \pm 0.2^{\#}$ & $0.40 \pm 0.1$ & $0.44 \pm 0.2$ & $0.40 \pm 0.2$ \\
\hline 5 & $0.68 \pm 0.2$ & $0.42 \pm 0.1^{\bullet}$ & $0.45 \pm 0.2^{\bullet}$ & $0.39 \pm 0.1$ \\
\hline \multicolumn{5}{|c|}{$\begin{array}{l}R \mathrm{rss} \\
\quad \mathrm{cmH}_{2} \mathrm{O} \cdot \mathrm{L}^{-1} \cdot \mathrm{s}^{-1}\end{array}$} \\
\hline 1 & $10.3 \pm 2.6^{\#}$ & $8.8 \pm 2.9$ & $8.9 \pm 3.2$ & $10.8 \pm 3.5^{5}$ \\
\hline 2 & $8.7 \pm 3.3^{\#}$ & $7.3 \pm 2.4$ & $8.9 \pm 2.0$ & $8.5 \pm 2.1$ \\
\hline 3 & $7.5 \pm 2.8^{\#}$ & $7.1 \pm 1.7$ & $8.4 \pm 2.1$ & $7.1 \pm 2.0$ \\
\hline 4 & $8.8 \pm 1.5^{\#}$ & $6.7 \pm 1.7$ & $7.3 \pm 1.1$ & $6.7 \pm 1.9$ \\
\hline 5 & $14.4 \pm 2.6$ & $7.2 \pm 1.4^{\oplus}$ & $7.0 \pm 1.7^{\natural}$ & $6.6 \pm 2.2$ \\
\hline
\end{tabular}

\#: significantly different from the fifth volume slice; $\%$ significantly different from the value of the corresponding volume slice with zero PEEP.

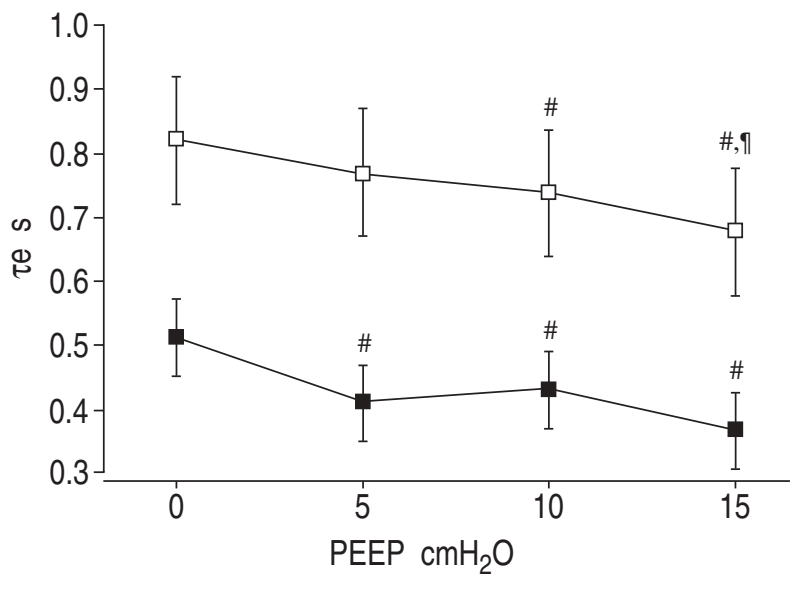

Fig. 3.-Mean time constant ( $\tau$ e) of all volume slices as a function of positive end-expiratory pressure (PEEP). Data are expressed as mean \pm SD. $\square$ : $\tau$ e; $\square$ : $\tau$ ers. ${ }^{\#}$ : significantly different from the value at zero PEEP. ': significantly different from the value at $5 \mathrm{cmH}_{2} \mathrm{O}$ PEEP.

\section{Discussion}

The main findings of this study were. 1) With ZEEP the respiratory system deflated through the endotracheal tube at a rate that progressively decreased toward the end of expiration, due to a considerable increase in expiratory resistance at low lung $V$. 2) Application of PEEP significantly decreased the expiratory resistance of the respiratory system and resulted in a relatively constant rate of deflation. 3) The overall rate of respiratory system deflation through the endotracheal tube increased considerably with increasing PEEP.

In this study, with ZEEP, nine out of 10 patients were flow limited during tidal expiration. Flow limitation was observed at the end of expiration and the flow-limited $V$ ranged between $0.05-0.15 \mathrm{~L}$. These results reconfirmed those obtained by KouTsoukou et al. [8], who showed that in the absence of externally

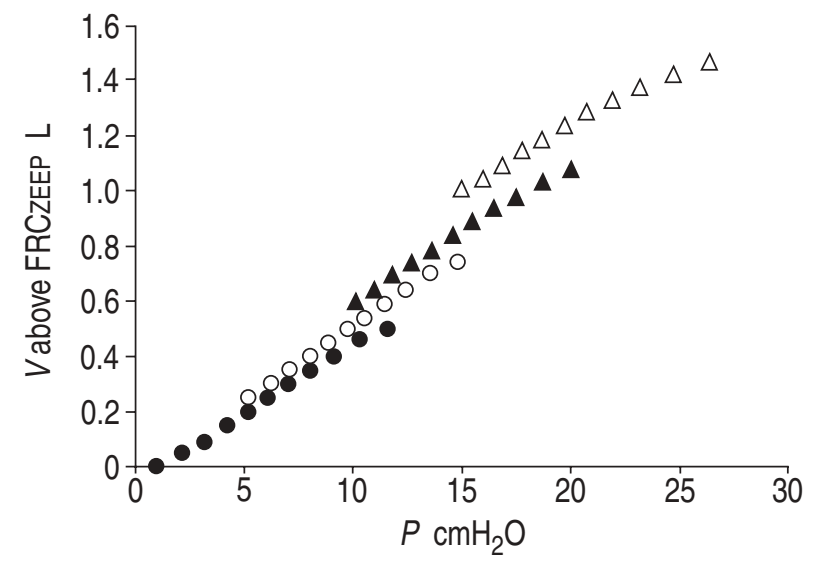

Fig. 4.-Mean group deflation the increase of tracheal pressure to a plateau level/volume $\left(\operatorname{Ptr}_{\mathrm{p}} / V\right)$ curve with different positive endexpiratory pressures (PEEP). $V$ was related to passive FRC at zero PEEP (ZEEP) (FRCZEEP). FRCZEEP was assigned a value of zero. $\mathrm{ZEEP}$; $\bigcirc \mathrm{cmH}_{2} \mathrm{O}$ PEEP; $\boldsymbol{\Delta}$ : $10 \mathrm{cmH}_{2} \mathrm{O}$ PEEP; $\triangle$ : $15 \mathrm{cmH}_{2} \mathrm{O}$ PEEP. 
applied PEEP most ARDS patients exhibited flow limitation during tidal expiration. It was shown further, that in all instances flow limitation was eliminated with PEEP as low as $5 \mathrm{cmH}_{2} \mathrm{O}$, indicating that low lung $V$ was the main determinant of flow limitation. The existence of flow limitation invalidates the calculation of expiratory resistance using the difference between alveolar and mouth pressures [9]. In flow-limited patients, upstream airway resistance at a specific $V$ should be calculated by dividing the difference between alveolar pressure and total pressure head at the choke point by the corresponding $V^{\prime}$ [23]. Total pressure head is very difficult to measure in humans and therefore other methods should be used to calculate expiratory resistance. The calculation of expiratory resistance in ARDS patients is further complicated by the nonlinear $P / V$ relationship of the respiratory system observed during tidal expiration, which precludes the use of a single value of elastance to estimate alveolar pressure. It follows that calculation of expiratory resistance in ARDS patients should take into account both flow limitation and the nonlinearities of the $P / V$ relationship. In this study both factors have been taken into consideration.

Modelling of passive expiration in patients with ARDS has shown that the time course of $V$ change during expiration should be described by a double rather than single exponential function. With two $\tau$, one characterizes a fast and the other a slow compartment [24]. In this study, consecutive $V$ slices of approximately $100 \mathrm{~mL}$ each (range $110-160 \mathrm{~mL}$ ) were used. In this relatively small $V$ range the $V / V^{\prime}$ relationship was highly linear with a correlation coefficient value approaching unity in all cases. Therefore, it is reasonable to assume that the $V$ course in each $V$ slice might be adequately described by a monoexponential function with a single $\tau$ e, enabling us to investigate the pattern of deflation during tidal breathing.

The $V / V^{\prime}$ relationship was obtained during passive deflation after a 3-s end-inspiratory pause. During that time elastic energy stored during inspiration in the viscoelastic elements of the respiratory system was dissipated and the pressure that initially drove expiratory $V^{\prime}$ was the static recoil pressure [24]. Thereafter, the effective recoil pressure that determined the expiratory $V^{\prime}$ was estimated by rapid airway occlusion and measuring $P \operatorname{tr}_{\text {init }}$ which at midtidal $V$ was $\sim 1 \mathrm{cmH}_{2} \mathrm{O}$ lower than the static recoil pressure $\left(P \operatorname{tr}_{\mathrm{p}}\right)$, due to regional ventilation and/or viscoelasticity (stress recovery) [11-13]. It follows that during expiration the $V / P \operatorname{tr}_{\text {init }}$ relationship dictates, in association with total airflow resistance, the $V / V^{\prime}$ relationship.

Effective as well as static deflation compliance, measured sequentially over small $V$ decrements varied over the range of $V \mathrm{~T}$. Particularly at ZEEP compliance had a bow shape, with the highest value observed at the midrange of $V \mathrm{~T}$. Conversely, at high PEEP, compliance progressively increased towards the end of expiration (table 3, fig. 2). The nonlinear behavior of the $P / V$ relationship over a commonly used $V \mathrm{~T}$ has been described for inflation compliance in surfacant-depleted animals [25]. Furthermore, in patients with acute lung injury [26] and in surfactantdepleted isolated rabbit lungs [27] respiratory system compliance, calculated during uninterrupted ventilation using multilinear regression analysis, has also been shown to be $V$ dependent. To the best of the authors' knowledge, this study is the first showing that in ARDS patients ventilated with commonly used $V$ T, nonlinear $P / V$ is also present during deflation. The observed pattern of compliance change during deflation is difficult to interpret precisely. The increase in compliance with deflation could be due either to a decrease in overdistension or to derecruitment [7]. The latter suggestion is likely with ZEEP and low PEEP, particularly if it is taken into account that the threshold closing $P$ for alveoli are usually lower than the threshold opening $P$ [28]. Thus, during deflation more alveoli are inflated than at an equivalent $P$ during inflation because their closing $P$ are lower than their opening $P$. This is probably exaggerated at the beginning of expiration, where $P$ are relatively high, resulting in low compliance [7]. With the progress of deflation more and more alveoli are closed, causing a proportionally greater change in $V$ than in $P$ (derecruitment), thus increasing the compliance. At the end of expiration the portion of the lung that remains open is relatively small causing a corresponding decrease in compliance. This is supported by the significant increase in compliance at the end of expiration with increasing PEEP, which keeps the lung relatively open. Indeed, with high PEEP compliance progressively increased throughtout expiration. Although a reduction of the overdistension may account for this increase, derecruitment with the progress of deflation even at the highest PEEP remains a possibility. The authors favour the second possibility as the predominant mechanism because, as for a given alveolar $P$, lung $V$ was significantly higher with $15 \mathrm{cmH}_{2} \mathrm{O}$ PEEP than with $10 \mathrm{cmH}_{2} \mathrm{O}$ PEEP, indicating recruitment (fig. 4). It follows that for a given lung $V$, compliance differed as a function of PEEP. Recent mathematical lung models and human data support the above interpretation [7, 29]. Conversely, if a reduction of overdistension was the predominant mechanism for the observed increase in compliance during deflation a similar compliance and alveolar pressure for a given $V$ between the two highest PEEP levels would be expected. Nevertheless, overdistention may contribute to an unknown extent, to this pattern.

This study has shown that the respiratory system deflated through the endotracheal tube with a $\tau$ e that progressively increased by $25 \%$ throughout expiration. This pattern of deflation was entirely due to increased resistance to airflow. Indeed, the calculated expiratory $R$ rs increased significantly at low lung $V$, probably reflecting closure or narrowing of small airways. Conversley, with PEEP the rate of deflation remained relatively constant throughout expiration. This was due to the significant effect of PEEP on $R \mathrm{rs}$, which either remained relatively constant throughout expiration (with 5 and 10 PEEP) or decreased toward the end of expiration (with 15 PEEP). With PEEP, Rrs was considerably lower at the end of expiration than with ZEEP. It is likely that PEEP decreased 
expiratory resistance by preventing airway closure or narrowing [29]. Furthermore, compared to ZEEP, the respiratory system emptied through the endotracheal tube faster with PEEP. The difference was substantial at the highest PEEP. Indeed, the mean ters of all $V$ slices decreased by $26 \%$ when PEEP increased from 0 to $15 \mathrm{cmH}_{2} \mathrm{O}$. This suggests that PEEP decreased the proportion of lung units with slow emptying dynamics.

The decrease in expiratory resistance with PEEP contrasts with the results reported by PESENTI et al. [30], also in ARDS patients, showing that PEEP increased the expiratory resistance. However, in the study of PESENTI et al. [30] expiratory resistance was calculated by estimating the alveolar $P$ assuming constant compliance. Furthermore, it was thought that the difference between alveolar and mouth $P$ represented the $P$ drop required to overcome the flow resistance. This study demonstrated clearly that respiratory system deflation compliance was not constant during tidal expiration, with the majority of the patients exhibiting flow limitation at low lung $V$. This renders the results of PESENTI et al. [30] questionable.

In accordance with previous studies [30, 31], total inspiratory resistance at end inspiration increased significantly with increasing PEEP due to a considerable increase in $\Delta \mathrm{R}$. This indicates that PEEP, increasing end-expiratory lung $V$, increases either stress adaptation phenomena or "pendelluft" or both. It has been suggested that overdistension of some lung units due to high PEEP might be responsible for the increase in $\Delta \mathrm{R}[30]$.

It would be of interest to see if the relatively constant and faster rate of deflation PEEP was associated with improvements in gas exchange. Arterial blood gasses were not measured in this study for two technical reasons. Firstly, in order to avoid dangerous hypoxaemia by reducing or removing PEEP, $F \mathrm{I}, \mathrm{O}_{2}$ was increased to $100 \%$ and kept at this level throughout the study. Secondly, the manipulation of $V \mathrm{~T}$ and breathing frequency, performed in order to avoid dynamic hyperinflation and to standardize the volume history, was applied only for short periods and thus steady state was not achieved. Nevertheless, animal data have shown that PEEP associated with a progressive decrease in respiratory system compliance during tidal inflation, reduces the pulmonary shunt and shifts perfusion toward areas with a normal ventilation-perfusion ratio [27]. In this study at the highest PEEP, a progressive increase in compliance during tidal expiration was observed, but is not known if a qualitatively similar improvement in gas exchange occurred. Finally, the faster rate of deflation observed with PEEP indicated that the proportion of fast lung units was increased and this might result in better gas exchange.

In conclusion, this study showed that without positive end-expiratory pressure the respiratory system in actute respiratory distress syndrome patients deflates with a rate that progressively decreases, due to a considerable increase in expiratory resistance at low lung volume. Application of positive end-expiratory pressure decreases the expiratory resistance, probably by preventing airway closure, and results in a relatively constant and fast rate of lung emptying.

\section{References}

1. Bernard GR, Artigas A, Brigham Kl, et al. AmericanEuropean consensus conference on ARDS. Am J Respir Crit Care Med 1994; 149: 818-824.

2. Marini JJ, Evans TW. Round table conference: acute lung injury, 15th-17th March 1997 Brussels, Belgium. Intensive Care Med 1998; 24: 878-883.

3. Marini JJ. Lung mechanics in the adult respiratory distress syndrome. Recent conceptual advances and implications for management. Clin Chest Med 1990; 11: 673-690.

4. Wright PE, Bernard GR. The role of airflow resistance in patients with the adult respiratory distress syndrome. Am Rev Respir Dis 1989; 139: 1169-1174.

5. Pelosi P, Crotti S, Brazzi L, Gattinoni L. Computed tomography in adult respiratory distress syndrome: what has it taught us? Eur Respir J 1996; 9: 1055-1062.

6. Guttmann J, Eberhard L, Fabry B, et al. Time constant/volume relationship of passive expiration in mechanically ventilated ARDS patients. Eur Respir $J$ 1995; 8: 114-120.

7. Hickling KG. Best compliance during a decremental but not incremental positive end expiratory pressure trial is related to open lung positive end-expiratory pressure. A mathematical model of acute respiratory distress syndrome lungs. Am J Respir Crit Care Med 2001; 163: 69-78.

8. Koutsoukou A, Armaganidis A, Stavrakaki-Kallergi $\mathrm{C}$, et al. Expiratory flow limitation and intrinsic positive end expiratory pressure at zero positive endexpiratory pressure in patients with adult respiratory distress syndrome. Am J Respir Crit Care Med 2000; 161: 1590-1596.

9. Elliott EA, Dawson SV. Test of wave-speed theory of flow limitation in elastic tubes. J Appl Physiol 1977; 43: $516-522$.

10. Georgopoulos D, Giannouli E, Patalkas D. Effects of extrinsic positive end-expiratory pressure on mechanically ventilated patients with chronic obstructive pulmonary disease and dynamic hyperinflation. Intensive Care Med 1993; 19: 197-203.

11. Bates JHT, Baconnier P, Milic-Emili J. A theoretical analysis of interrupter technique for measuring respiratory mechanics. J Appl Physiol 1988; 64: 2204-2214.

12. Bates JHT, Brown KA, Kochi T. Respiratory mechanics in the normal dog determined by expiratory flow interruption. J Appl Physiol 1989; 67: 2276-2285.

13. Jonson B, Beydon L, Brauer K, Ma Isson C, Valind S, Grtzell $\mathrm{H}$. Mechanisms of respiratory system in healthy anesthetized humans with emphasis on viscoelastic properties. J Appl Physiol 1993; 75: 132-140.

14. Valta P, Corbeil C, Lavoie A, et al. Detection of expiratory flow limitation during mechanical ventilation. Am J Respir Crit Care Med 1994; 150: 1311-1317.

15. Zin WA, Pengelly LD, Milic-Emili J. Single-breath method for measurement of respiratory mechanics in anesthetized animals. $J$ Appl Physiol 1982; 52: $1266-1271$.

16. Guttmann J, Eberhard L, Haberthur C, et al. Detection of endotracheal tube obstruction by analysis of the expiratory flow signal. Intensive Care Med 1998; 24: 1163-1172. 
17. Venegas JG, Harris RS, Simon BA. A comprehensive equation for the pulmonary pressure-volume curve. J Appl Physiol 1998; 84: 389-395.

18. Harris RS, Hess DR, Venegas JG. An objective analysis of the pressure-volume curve in the acute respiratory distress syndrome. Am J Respir Crit Care Med 2000; 161: 432-439.

19. Kondili E, Prinianakis G, Xoeing S, Chatzakis G, Georgopoulos D. Low flow pressure time curve in patients with ARDS. Intensive Care Med 2000; 26: 1756-1763.

20. Gottfried SB, Rossi A, Higgs BD, Zocchi L, Grassino A, Milic-Emili J. Respiratory mechanics in mechanically ventilated patients with respiratory failure. $J \mathrm{Appl}$ Physiol 1985; 58: 1849-1858.

21. Bates JHT, Rossi A, Milic-Emili J. Analysis of the behaviour of the respiratory system with constant inspiratory flow. J Appl Physiol 1985; 58: 1840-1848.

22. Kochi T, Okubo S, Zin WA, Milic-Emili J. Flow and volume dependence of pulmonary mechanics in anaesthetized cats. J Appl Physiol 1988; 64: 441-450.

23. Georgopoulos D, Mink SN, Oppenheimer L, Anthonisen NR. How is maximal expiratory flow reduced in canine psotpneumonectomy lung growth? J Appl Physiol 1991; 71: 834-840.

24. Chelucci GL, Dall' Ava-Santucci J, Dhainaut JF, et al. A modelling of passive expiration in patients with adult respiratory distress syndrome. Eur Respir J 1993; 6: 785-790.

25. Lichtwarck-Aschoff M, Mols G, Hedlund AJ, et al.
Compliance is nonlinear over tidal volume irrespective of positive end-expiratory pressure level in surfactantdepleted piglets. Am J Respir Crit Care Med 2000; 162: 2125-2133.

26. Mols G, Brandes I, Kessler V, et al. Volumedependent compliance in ARDS: proposal of a new diagnostic concept. Intensive Care Med 1999; 25: 1084-1091.

27. Mols G, Hermle G, Schubert J, et al. Volumedependent compliance and ventilationperfusion mismatch in surfactant-depleted isolated rabbit lungs. Crit Care Med 2001; 29: 144-151.

28. Otis DR, Petak F, Hantos Z, Fredberg JJ, Kamm RD. Airway closure and reopening assessed by the alveolar capsule oscillation technique. J Appl Physiol 1996; 80: 2077-2084.

29. Jonson B, Richard JC, Straus C, Mancebo J, Lemaire F, Brochard L. Pressure-volume curves and compliance in acute lung injury: evidence of recruitment above the lower inflection point. Am J Respir Crit Care Med 1999; 159: 1172-1178.

30. Pesenti A, Pelosi P, Rossi N, Virtuani A, Brazzi L, Rossi A. The effects of positive end-expiratory pressure on respiratory resistance in patients with the adult respiratory distress syndrome and in normal anesthetized subjects. Am Rev Respir Dis 1991; 144: 101-107.

31. Eissa NT, Ranieri VM, Corbeil C, Chasse M, Braidy J, Milic-Emili J. Effect of PEEP on the mechanics of the respiratory system in ARDS patients. $J$ Appl Physiol 1992; 73: 1728-1735. 